Вип. 1, 2019

УДК 621.313.3

I. Р. Гавдьо

Національний університет “Львівська політехніка", кафедра електромехатроніки та комп'ютеризованих електромеханічних систем, fireballua402@gmail.com

\title{
МАТЕМАТИЧНА МОДЕЛЬ МАГНІТНОГО СТАНУ КОЛЕКТОРНОГО ДВИГУНА ІЗ МАГНІТОЕЛЕКТРИЧНИМ ЗБУДЖЕННЯМ
}

https://doi.org/10.23939/sepes2019.01.010

(C) Гавдьо I. P., 2019

Сьогодні існує тенденція до заміни мікродвигунів постійного струму з електромагнітним збудженням на двигуни зі збудженням від постійних магнітів (ДПС ПМ). Враховуючи широке застосування ДПС ПМ, актуальним с створення математичних моделей цього типу двигуна. Мета статті - розроблення математичної моделі магнітного стану ДПС ПМ на основі теорії електричних та магнітних кіл, яка дає змогу за заданими значеннями характеристики розмагнічування магніту та миттєвими значеннями струмів якоря знайти розподіл магнітних потоків (індукцій) в усіх частинах магнітопроводу двигуна. Математичну модель ДПС ПМ розроблено на основі розгалуженої заступної схеми магнітного кола із зосередженими параметрами та 3 високим рівнем деталізації магнітопроводу. Магнітне коло ДПС ПМ умовно розділено на окремі ділянки, в межах кожної 3 яких поле вважасмо однорідним. Ділянкам магнітопроводу з електротехнічної сталі та зубцевому шару якоря на заступній схемі відповідають нелінійні магнітні опори, які задано характеристиками $F[\Phi]$ як залежностями спадів магніторушійних сил від магнітних потоків. Ділянкам із повітряним проміжком відповідають постійні магнітні опори. Постійний магніт подаємо зосередженою магніторушійною силою (МРС), заданою характеристикою розмагнічування $F_{M}\left[\Phi_{M}\right]$. Якір з повітряним проміжком радіальними площинами розділясмо на $s=m+n$ ділянок у межах полюсної поділки. 3 них $m$ рівномірних ділянок відповідають частині якоря, яка розміщена під магнітом, а $n$ рівномірних ділянок - у просторі між магнітами. Вихідну систему рівнянь складено для однісї полюсної поділки за методом контурних потоків, які є первинними невідомими. Вихідна система рівнянь перетворюсться - спади магнітних напруг на нелінійних опорах подано залежностями від потоків віток. Характеристику розмагнічування магніту подано як рівняння прямої, яка розташована у другому квадранті й перетинає вісь $\mathrm{X}$ у точці залишкового магнітного потоку $\Phi_{r}$, а вісь Y у точці, що відповідає повній намагнічуючій силі магніту $-F_{c}$. Отриману нелінійну систему алгебричних рівнянь доцільно розв'язувати ітераційним методом Ньютона. Розроблена математична модель магнітного стану ДПС ПМ може слугувати основою для створення математичних моделей розрахунку перехідних процесів та статичних характеристик цього типу двигуна.

Ключові слова: колекторний двигун; магнітоелектричне збудження; магнітопровід; заступна схема; система рівнянь; математична модель. 


\section{Постановка проблеми}

ДПС ПМ внаслідок відсутності втрат на збудження мають вищий коефіцієнт корисної дії та меншу масу на одиницю потужності порівняно із колекторними мікродвигунами електромагнітного збудження. Нині простежується тенденція до заміни мікродвигунів постійного струму 3 електромагнітним збудженням на ДПС ПМ. Згідно з [1] 70 \% виготовлених ДПС ПМ призначені для автомобілів. На другому місці стосовно сфери застосування ДПС ПМ - електропобутові прилади та переносний електроінструмент. ДПС ПМ також широко застосовуються у комп'ютерній промисловості як приводи жорстких дисків.

\section{Актуальність досліджень}

Враховуючи широке застосування ДПС ПМ, актуалізується створення математичних моделей цього типу двигуна, придатних як для розроблення нових, так і для оптимізації наявних зразків ДПС ПМ.

\section{Мета та завдання статті}

Мета статті - розроблення математичної моделі магнітного стану ДПС ПМ на основі теорії електричних та магнітних кіл, яка дає змогу за заданими значеннями характеристики розмагнічування магніту та миттєвими значеннями струмів якоря знайти розподіл магнітних потоків (індукцій) в усіх частинах магнітопроводу двигуна. В статті вирішено такі завдання: складання заступної схеми магнітопроводу ДПС ПМ на основі найпоширенішої конструкції із радіальними магнітами; опис цієї заступної схеми системою рівнянь; вибір математичного методу розв'язання системи рівнянь.

\section{Аналіз останніх досліджень}

В [2] розглянуто спрощену лінійну модель дискового магнітоелектричного двигуна. Отримані аналітичні вирази дають змогу розрахувати габаритні розміри двигуна. Результати розрахунків ДПС ПМ, виконаних на дво- та тривимірних моделях із поєднанням польових та колових методів, наведено в [1,3]. Використання спрощених моделей [2] дає змогу отримати аналітичні вирази, які можна використовувати для наближених інженерних розрахунків. Методи, які грунтуються на розрахунку магнітного поля $[1,3]$, найточніші, однак доволі трудомісткі.

Розроблена в [4] математична модель асинхронного двигуна 3 екранованими полюсами грунтується на поданні магнітного кола машини заступною схемою і дає змогу достатньо адекватно розраховувати перехідні процеси та статичні характеристики. На наш погляд, аналіз процесів i розрахунок характеристик ДПС ПМ із достатньою для інженерної практики точністю можна виконувати методами електричних та магнітних кіл і в [5] викладено основи математичної моделі ДПС ПМ із застосуванням вищезгаданих методів. У цій статті розвинено математичну модель, наведену в [5], стосовно розрахунку магнітного стану ДПС ПМ.

\section{Виклад основного матеріалу}

Математичну модель ДПС ПМ розроблено на основі розгалуженої заступної схеми магнітного кола із зосередженими параметрами та з високим рівнем деталізації магнітопроводу (див. рисунок). В основу математичної ДПС ПМ покладемо допущення, викладені в [5]. Наведена на рисунку схема удосконалена порівняно зі схемою, поданою у [5], - введено магнітні опори $R_{K}$ через коронки зубців. Магнітне коло ДПС ПМ умовно розділимо на окремі ділянки, в межах кожної iз яких поле вважаємо однорідним. Ділянкам магнітопроводу з електротехнічної сталі та зубцевому шару якоря на заступній схемі відповідають нелінійні магнітні опори (MO), які задані характеристиками $F[\Phi]$ як залежностями спадів МРС від магнітних потоків. Ділянкам із повітряним проміжком відповідають постійні МО. 


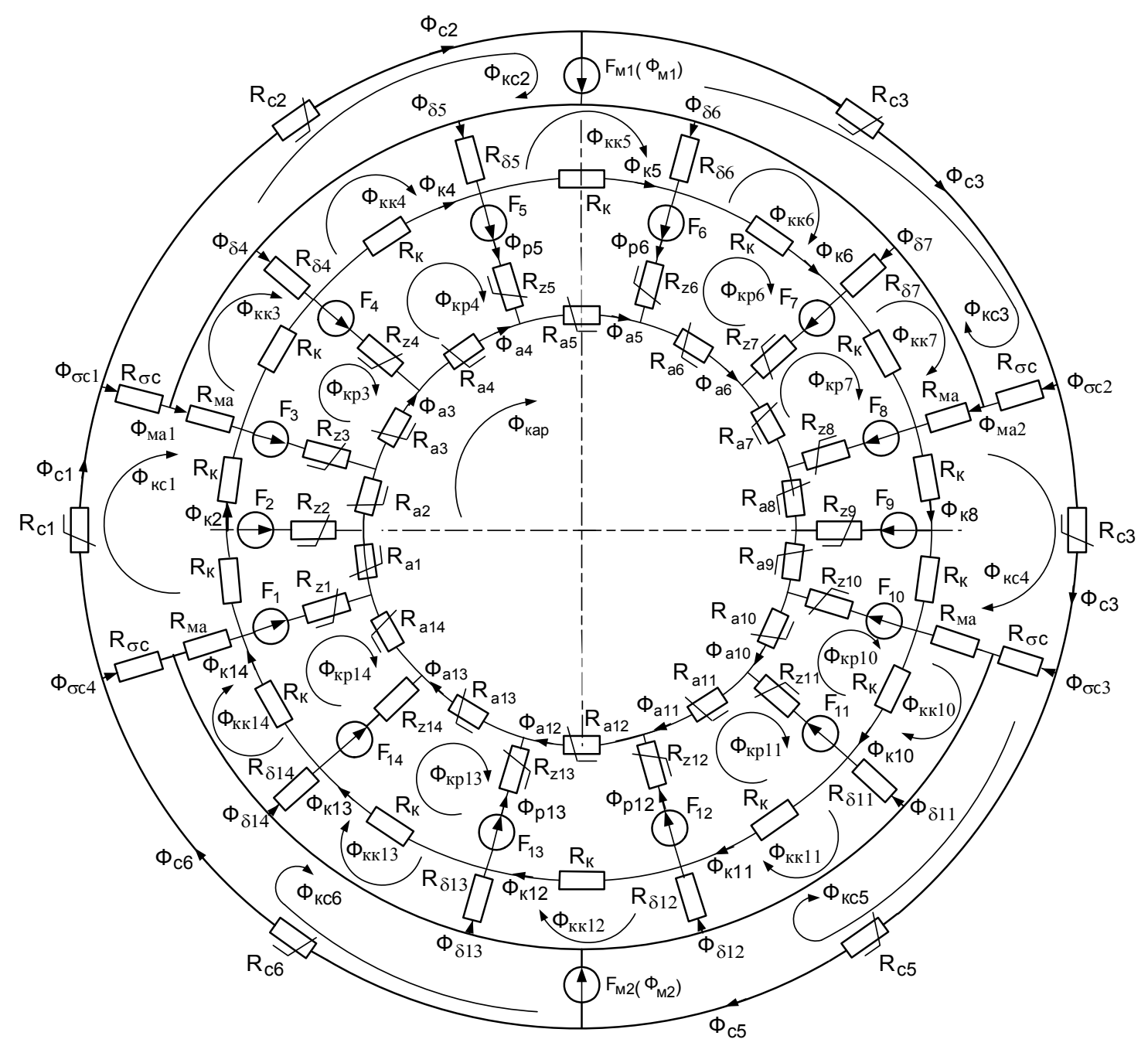

Заступна схема магнітного кола ДПС ПМ

Якір із повітряним проміжком радіальними площинами розділяємо на $s=m+n$ ділянок у межах полюсної поділки. Із них $\boldsymbol{m}$ рівномірних ділянок відповідають частині якоря, розташованій під магнітом, а $\boldsymbol{n}$ рівномірних ділянок - у просторі між магнітами.

Ділянки якоря під магнітом, які містять повітряний проміжок і зубцевий шар, на заступній схемі подаємо послідовно розташованими у радіальному напрямку елементами: постійним МО повітряного проміжку $R_{\delta}$, МРС якоря $F$ та нелінійним МО зубцевої зони $R_{z}$. Між цими елементами містяться поперечні вітки із постійним МО $R_{K}$, який відповідає магнітному потоку через коронки зубців, та з нелінійним МО ярма якоря $R_{a}$.

Нелінійний МО $R_{z}$ задано характеристикою $F_{z}\left[\Phi_{z}\right]$, де $F_{z}$ є спадом МРС у зубцевій зоні, а $\Phi_{z}-$ магнітним потоком у зубцевій зоні. Нелінійний МО $R_{a}$, задано характеристикою $F_{a}\left[\Phi_{a}\right]$, де $F_{a}$ та $\Phi_{a}-$ спад МРС і магнітний потік ярма якоря.

Ділянки якоря між полюсами, суміжні з ділянками під магнітом, на заступній схемі подаємо послідовно розташованими у радіальному напрямку елементами: постійними МО $R_{\sigma c}$ та $R_{M a}$, МРС якоря $F$ та нелінійним МО зубцевої зони $R_{z}$. Постійний МО $R_{\sigma c}$ відповідає потокам розсіяння між бічною поверхнею магніту і внутрішньою поверхнею ярма статора, а опір $R_{\text {мa }}$ - потокам між бічною поверхнею магніту і якорем. Ділянки якоря між полюсами на заступній схемі подаються аналогічно до ділянок під магнітом за винятком постійного МО повітряного проміжку $R_{\delta}$. 
У схемі, наведеній на рис. $1,-m=4 ; n=3$. Постійний магніт подаємо зосередженою МРС, заданою характеристикою розмагнічування $F_{M}\left[\Phi_{M}\right]$. Ділянки ярма статора, які прилягають до поверхні магнітів, замінюємо нелінійними $\mathrm{MO} R_{c 2}, R_{c 3}, R_{c 5}, R_{c 6}$, заданими характеристиками $F_{c}$ $\left[\Phi_{c}\right]$, де $F_{c}$ та $\Phi_{c}-$ спад MPC і магнітний потік ярма статора у цій ділянці. Ділянки ярма статора, які не дотикаються до поверхні магнітів, замінюємо нелінійними $\mathrm{MO} R_{c 1}, R_{c 4}$, заданими характеристиками $F_{c}\left[\Phi_{c}\right]$, де $F_{c}$ та $\Phi_{c}-$ спад MPC і магнітний потік ярма статора у цій ділянці.

Схема містить такі контурні потоки:

$\Phi_{\kappa c 1}, \Phi_{\kappa c 4}$ - потоки у контурах: ярмо статора - потоки бічної поверхні магніту через постійні MO $R_{\sigma c}$ і $R_{м a}$ - потоки через коронки зубців якоря - потоки бічної поверхні магніту через постійні MO $R_{\sigma c}$ і $R_{M a}-$ ярмо статора;

$\Phi_{\kappa c 2}, \Phi_{\kappa c 3}, \Phi_{\kappa c 5}, \Phi_{\kappa c 6}$ - потоки у контурах: ярмо статора - намагнічуюча сила магніту $F_{M}-$ постійний $\mathrm{MO} R_{\sigma c}-$ ярмо статора;

$\Phi_{\kappa \kappa n}, \Phi_{\kappa \kappa s}, \Phi_{\kappa \kappa(n+s)}, \Phi_{\kappa \kappa 2 s}-$ потоки у контурах: повітряний проміжок - коронки зубців якоря постійний $\mathrm{MO} \mathrm{R}_{\text {ма }}-$ повітряний проміжок;

$\Phi_{\kappa \kappa(n+1)}, \ldots \Phi_{\kappa \kappa(s-1)}, \Phi_{\kappa \kappa(n+1+s)}, \ldots \Phi_{\kappa \kappa(2 s-1)}$ - потоки у контурах: повітряний проміжок коронки зубців якоря - повітряний проміжок;

$\Phi_{\kappa p 1}, \ldots \Phi_{\kappa р 2 s}-$ потоки у контурах ротора; $\Phi_{\kappa a p}-$ контурний потік через ділянки ярма ротора.

У схемі $є$ такі потоки у вітках:

$\Phi_{c 1}, \ldots \Phi_{c 6}-$ потоки у вітках ярма статора;

$\Phi_{\delta(n+1), \ldots} \Phi_{\delta s}, \Phi_{\delta(s+n+1), . .} \Phi_{\delta 2 \mathrm{~s}}-$ потоки у ділянках повітряного проміжку;

$\Phi_{p 1}, \ldots \Phi_{p 2 s}-$ потоки у радіальних вітках ротора;

$\Phi_{\kappa 1}, \ldots \Phi_{\kappa 2 s}-$ потоки через коронки зубців якоря; $\Phi_{a 1}, \ldots \Phi_{a 2 s}-$ потоки у вітках ярма ротора;

$\Phi_{\sigma s} 1, \ldots \Phi_{\sigma s} 4-$ потоки розсіяння між бічною поверхнею магніту і внутрішньою поверхнею ярма статора; $\Phi_{\text {мa } 1}, \ldots \Phi_{\text {мa4 }}$ - потоки між бічною поверхнею магніту і якорем.

Віток у заступній схемі ДПС з ПМ $-2[3 s+m+7]$. Кількість вузлів заступної схеми $-q=2[2 s+$ $+4]$. Кількість незалежних контурів $-2[s+(m+1)+3]+1$.

Кількість незалежних контурів менша від кількості вузлів для будь-яких значень $m$ та $s$, оскільки $2(m+1)<2 s+1$. Отже, для розрахунку заступної схеми доцільно застосувати метод контурних потоків.

Із заступної схеми видно, що достатньо використати $s+(m+1)+3$ контури, які відносяться до однієї полюсної поділки.

Умови симетрії контурних потоків:

$$
\begin{aligned}
& \Phi_{\kappa c 4}=-\Phi_{\kappa c 1} ; \quad \Phi_{\kappa c 5}=-\Phi_{\kappa c 2} ; \quad \Phi_{\kappa c 6}=-\Phi_{\kappa c 3} ; \quad \Phi_{\kappa \kappa(n+s)}=-\Phi_{\kappa \kappa n} ; \\
& \Phi_{\kappa \kappa 2 s}=-\Phi_{\kappa k s} ; \quad \Phi_{\kappa \kappa(n+i+s)}=\Phi_{\kappa \kappa(n+i)} ; \quad i=1,2, \ldots(m-1) ; \quad \Phi_{\kappa p i+s}=-\Phi_{\kappa p i} ; \quad i=1,2, \ldots s ;
\end{aligned}
$$

Умови симетрії потоків у вітках:

$$
\begin{aligned}
& \Phi_{c 4}=-\Phi_{c 1} ; \quad \Phi_{c 5}=-\Phi_{c 2} ; \quad \Phi_{c 6}=-\Phi_{c 3} ; \quad \Phi_{M a 3}=-\Phi_{M a 1} ; \quad \Phi_{M a 4}=-\Phi_{M a 2} \\
& \Phi_{\sigma c 3}=-\Phi_{\sigma c 1} ; \quad \Phi_{\sigma c 4}=-\Phi_{\sigma c 2} ; \quad \Phi_{\delta(n+i+s)}=-\Phi_{\delta(n+i)} ; i=1,2, \ldots m ; \\
& \Phi_{p(i+s)}=-\Phi_{p i} ; \quad i=1,2, \ldots s ; \quad \Phi_{\kappa(i+s)}=-\Phi_{\kappa i} ; \quad i=1,2, \ldots s ; \\
& \Phi_{a(i+s)}=-\Phi_{a i} ; i=3, \ldots s-1 .
\end{aligned}
$$

Намагнічуюча сила $i$-ї ділянки обмотки якоря

$$
T_{i}=T_{\mathcal{M}}\left(2 \gamma_{i} / \tau\right) ; \quad T_{\mathcal{M}}=(N / 4 p)\left(i_{a} / 2 a\right),
$$




\section{I. Р. Гавдьо}

де $\gamma_{i}$ - кут, що визначає положення $i$-ї ділянки обмотки якоря відносно осі $d ; \tau-$ полюсна поділка; $i_{a}$ - струм у колі якоря; $N, 2 a$ - кількість провідників і паралельних гілок обмотки якоря; $p-$ кількість пар полюсів.

Нелінійна система рівнянь, складена за методом контурних потоків для однісї полюсної поділки, міститиме $s$ рівнянь для контурів ротора (коронки зубців - зубцева зона - ярмо якоря зубцева зона - коронки зубців), $n$-не рівняння для контуру “повітряний проміжок - коронки зубців постійний МО $R_{M a}$ - повітряний проміжок”, $(m-1)$ рівнянь для контурів “повітряний проміжок коронки зубців - повітряний проміжок”, $s$-те рівняння для контуру “повітряний проміжок коронки зубців - постійний МО $R_{M a}$ - повітряний проміжок” та три рівняння для контурних потоків $\Phi_{\kappa c 1}, \Phi_{\kappa c 2}, \Phi_{\kappa c 3}$. Запишемо систему рівнянь (2) з урахуванням умов симетрії:

$$
\begin{aligned}
& F_{z 1}\left[\Phi_{\kappa p 1}+\Phi_{k p s}\right]+R_{\kappa}\left(\Phi_{\kappa p 1}-\Phi_{\kappa c 1}\right)+F_{z 2}\left[\Phi_{k p 1}-\Phi_{\kappa p 2}\right]+F_{a 1}\left[\Phi_{\kappa p 1}\right]+F_{1}-F_{2}=0 ; \\
& F_{z 2}\left[\Phi_{\kappa p 2}-\Phi_{\kappa p 1}\right]+R_{\kappa}\left(\Phi_{\kappa p 2}-\Phi_{\kappa c 1}\right)+F_{z 3}\left[\Phi_{\kappa p 2}-\Phi_{\kappa p 3}\right]+F_{a 2}\left[\Phi_{\kappa p 2}\right]+F_{2}-F_{3}=0 \\
& F_{z n}\left[\Phi_{\kappa p n}-\Phi_{\kappa p(n-1)}\right]+R_{\kappa}\left(\Phi_{\kappa p n}-\Phi_{\kappa \kappa n}\right)+F_{z(n+1)}\left[\Phi_{\kappa p n}-\Phi_{\kappa p(n+1)}\right]+F_{a n}\left[\Phi_{\kappa p n}\right]+F_{n}-F_{(n-1)}=0 \text {; } \\
& F_{z s}\left[\Phi_{k p s}-\Phi_{k p(s-1)}\right]+R_{\kappa}\left(\Phi_{k p s}-\Phi_{\kappa k s}\right)+F_{z s+1}\left[\Phi_{k p s}+\Phi_{\kappa p 1}\right]+F_{a s}\left[\Phi_{k p s}\right]+F_{s}+F_{1}=0 ; \\
& R_{\text {мa }}\left(\Phi_{\kappa \kappa n}-\Phi_{\kappa c 1}\right)+R_{\delta(n+1)}\left(\Phi_{\kappa \kappa n}-\Phi_{\kappa \kappa(n+1)}\right)+R_{\kappa}\left(\Phi_{\kappa \kappa n}-\Phi_{\kappa p n}\right)=0 \text {; } \\
& R_{\delta(n+1)}\left(\Phi_{\kappa \kappa(n+1)}-\Phi_{\kappa \kappa n}\right)+R_{\delta(n+2)}\left(\Phi_{\kappa \kappa(n+1)}-\Phi_{\kappa \kappa(n+2)}\right)+R_{\kappa}\left(\Phi_{\kappa \kappa(n+1)}-\Phi_{\kappa p(n+1)}\right)=0 ; \\
& R_{\delta(s-1)}\left(\Phi_{\kappa \kappa(s-1)}-\Phi_{\kappa \kappa(s-2)}\right)+R_{\delta s}\left(\Phi_{\kappa \kappa(s-1)}-\Phi_{\kappa \kappa s}\right)+R_{\kappa}\left(\Phi_{\kappa \kappa(s-1)}-\Phi_{\kappa p(s-1)}\right)=0 \\
& R_{M a}\left(\Phi_{\kappa \kappa s}+\Phi_{\kappa c 1}\right)+R_{\delta s}\left(\Phi_{\kappa \kappa s}-\Phi_{\kappa \kappa(s+1)}\right)+R_{\kappa}\left(\Phi_{\kappa K s}-\Phi_{\kappa p s}\right)=0 ; \\
& R_{\sigma c}\left(\Phi_{\kappa c 1}-\Phi_{\kappa c 2}\right)+R_{\mu a}\left(\Phi_{\kappa c 1}-\Phi_{\kappa \kappa n}\right)+R_{\kappa}\left(\Phi_{\kappa c 1}-\Phi_{\kappa p 2}\right)+R_{\kappa}\left(\Phi_{\kappa c 1}-\Phi_{\kappa p 1}\right)+R_{\mu a}\left(\Phi_{\kappa c 1}+\Phi_{\kappa \kappa s}\right)+ \\
& +R_{\sigma c}\left(\Phi_{\kappa c 1}+\Phi_{\kappa c 3}\right)+F_{c 1}\left[\Phi_{\kappa c 1}\right]=0 \text {; } \\
& R_{\sigma c}\left(\Phi_{\kappa c 2}-\Phi_{\kappa c 1}\right)+F_{c 2}\left[\Phi_{\kappa c 2}\right]-F_{M 1}\left[\Phi_{M 1}\right]=0 ; \\
& R_{\sigma c}\left(\Phi_{\kappa c 3}+\Phi_{\kappa c 1}\right)+F_{c 3}\left[\Phi_{\kappa c 3}\right]+F_{\mu 1}\left[\Phi_{M 1}\right]=0 .
\end{aligned}
$$

Об'єднаймо магнітні потоки у вітках та контурах у вектори-стовпці.

Потоки у вітках:

$$
\begin{aligned}
& \bar{\Phi}_{\delta}=\left(\Phi_{\delta 3}, \ldots \Phi_{\delta \mathrm{s}-1}\right) ; \quad \bar{\Phi}_{\delta}=\left(\Phi_{\kappa 1}, \ldots \Phi_{\kappa \mathrm{s}}\right) ; \quad \bar{\Phi}_{a}=\left(\Phi_{a 1}, \ldots \Phi_{a \mathrm{~s}}\right) ; \\
& \bar{\Phi}_{p}=\left(\Phi_{p 1}, \ldots \Phi_{p \mathrm{~s}}\right) ; \quad \bar{\Phi}_{c}=\left(\Phi_{c 1}, \Phi_{c 2}\right) ; \quad \bar{\Phi}_{\sigma c}=\left(\Phi_{\sigma c 1}, \Phi_{\sigma c 2}\right) ; \quad \bar{\Phi}_{\mu a}=\left(\Phi_{м a 1}, \Phi_{м a 2}\right) \text {. }
\end{aligned}
$$

Потоки у контурах:

$$
\bar{\Phi}_{p}=\left(\Phi_{p 1}, \ldots \Phi_{p \mathrm{~s}}\right) ; \quad \bar{\Phi}_{\kappa c}=\left(\Phi_{\kappa c 1}, \ldots \Phi_{p \kappa \mathrm{c} 2}\right) ; \bar{\Phi}_{\kappa \kappa}=\left(\Phi_{\kappa \kappa 2}, \ldots \Phi_{\kappa \kappa \mathrm{s}-1}\right) ; \quad \bar{\Phi}_{\kappa \sigma}=\left(\Phi_{\kappa \sigma 1}, \Phi_{\kappa \sigma 2}\right)
$$

Перетворимо систему рівнянь (2) до вигляду, зручного для знаходження матриці Якобі. Для цього на нелінійних ділянках врахуємо зв'язки між контурними потоками і потоками у вітках, а добутки постійних магнітних опорів на різницю контурних потоків залишимо без змін. Характеристику розмагнічування магніту запишемо як рівняння прямої, яка розташована у другому квадранті й перетинає вісь $X$ у точці залишкового магнітного потоку $\Phi_{r}$, а вісь $Y$ у точці, що відповідає повній намагнічуючій силі магніту $-F_{c}$ :

$$
\left(F_{M} /-F_{c}\right)+\left(\Phi_{M} / \Phi_{r}\right)=1,
$$

де $F_{\mathcal{M}}$ та $\Phi_{\mathcal{M}}$ - поточні координати робочої точки магніту.

Подамо (3) у вигляді

$$
F_{M}=\Phi_{M}\left(F_{c} / \Phi_{r}\right)-F_{c}
$$


Позначивши $k_{M}=F_{c} / \Phi_{r}$ та врахувавши, що $\Phi_{M}=\Phi_{\kappa c 2}-\Phi_{\kappa c 3}$, отримаємо

$$
F_{M}=k_{M}\left(\Phi_{\kappa c 2}-\Phi_{\kappa c 3}\right)-F_{c .}
$$

3 урахуванням (5) система рівнянь (2) набуде вигляду

$$
\begin{aligned}
& -F_{z 1}\left[\Phi_{p 1}\right]+R_{\kappa}\left(\Phi_{\kappa p 1}-\Phi_{\kappa c 1}\right)+F_{z 2}\left[\Phi_{p 2}\right]-F_{a 1}\left[\Phi_{a 1}\right]+F_{1}-F_{2}=0 ; \\
& -F_{z 2}\left[\Phi_{p 2}\right]+R_{\kappa}\left(\Phi_{\kappa p 2}-\Phi_{\kappa c 1}\right)+F_{z 3}\left[\Phi_{p 3}\right]-F_{a 2}\left[\Phi_{a 2}\right]+F_{2}-F_{3}=0 ; \\
& -F_{z n}\left[\Phi_{p n}\right]+R_{\kappa}\left(\Phi_{\kappa p n}-\Phi_{\kappa \kappa n}\right)+F_{z(n+1)}\left[\Phi_{p(n+1)}\right]-F_{a n}\left[\Phi_{p n}\right]+F_{n}-F_{(n-1)}=0 ; \\
& -F_{z s}\left[\Phi_{p s}\right]+R_{\kappa}\left(\Phi_{\kappa p s}-\Phi_{\kappa \kappa s}\right)+F_{z s+1}\left[\Phi_{p(s+1)}\right]-F_{a s}\left[\Phi_{a s}\right]+F_{s}+F_{1}=0 ; \\
& R_{\mathcal{M} a}\left(\Phi_{\kappa \kappa n}-\Phi_{\kappa c 1}\right)+R_{\delta(n+1)}\left(\Phi_{\kappa \kappa n}-\Phi_{\kappa \kappa(n+1)}\right)+R_{\kappa}\left(\Phi_{\kappa \kappa n}-\Phi_{\kappa p n}\right)=0 \text {; } \\
& R_{\delta(n+1)}\left(\Phi_{\kappa \kappa(n+1)}-\Phi_{\kappa \kappa n}\right)+R_{\delta(n+2)}\left(\Phi_{\kappa \kappa(n+1)}-\Phi_{\kappa \kappa(n+2)}\right)+R_{\kappa}\left(\Phi_{\kappa \kappa(n+1)}-\Phi_{\kappa p(n+1)}\right)=0 ; \\
& R_{\delta(s-1)}\left(\Phi_{\kappa \kappa(s-1)}-\Phi_{\kappa \kappa(s-2)}\right)+R_{\delta s}\left(\Phi_{\kappa \kappa(s-1)}-\Phi_{\kappa \kappa s}\right)+R_{\kappa}\left(\Phi_{\kappa \kappa(s-1)}-\Phi_{\kappa p(s-1)}\right)=0 ; \\
& R_{\mathcal{M} a}\left(\Phi_{\kappa \kappa s}+\Phi_{\kappa c 1}\right)+R_{\delta s}\left(\Phi_{\kappa \kappa s}-\Phi_{\kappa \kappa(s+1)}\right)+R_{\kappa}\left(\Phi_{\kappa \kappa s}-\Phi_{\kappa p s}\right)=0 \\
& R_{\sigma c}\left(\Phi_{\kappa c 1}-\Phi_{\kappa c 2}\right)+R_{M a}\left(\Phi_{\kappa c 1}-\Phi_{\kappa \kappa n}\right)+R_{\kappa}\left(\Phi_{\kappa c 1}-\Phi_{\kappa p 2}\right)+R_{\kappa}\left(\Phi_{\kappa c 1}-\Phi_{\kappa p 1}\right)+R_{M a}\left(\Phi_{\kappa c 1}+\Phi_{\kappa k s}\right)+ \\
& +R_{\sigma c}\left(\Phi_{\kappa c 1}+\Phi_{\kappa c 3}\right)+F_{c 1}\left[\Phi_{c 1}\right]=0 \text {; } \\
& R_{\sigma c}\left(\Phi_{\kappa c 2}-\Phi_{\kappa c 1}\right)+F_{c 2}\left[\Phi_{c 2}\right]-k_{M}\left(\Phi_{\kappa c 2}-\Phi_{\kappa c 3}\right)+F_{c}=0 \\
& R_{\sigma c}\left(\Phi_{\kappa c 3}+\Phi_{\kappa c 1}\right)+F_{c 3}\left[\Phi_{c 3}\right]+k_{M}\left(\Phi_{\kappa c 2}-\Phi_{\kappa c 3}\right)-F_{c}=0 .
\end{aligned}
$$

Нелінійну систему алгебричних рівнянь (6) доцільно розв'язувати ітераційним методом Ньютона.

\section{Висновки}

Розроблену математичну модель магнітного стану ДПС ПМ можна покласти в основу створення математичних моделей розрахунку перехідних процесів та статичних характеристик ДПС ПМ.

\section{Перспективи подальших досліджень}

Надалі необхідно на основі запропонованої математичної моделі розробити математичні моделі розрахунку перехідних процесів та статичних характеристик ДПС ПМ.

\section{Список використаних джерел}

1. Dudzikowski I. Silniki komutatorowe wzbudzane magnesami trwalymi // Prace Naukowe Instytutu Maszyn, Napędów i Pomiarów Elektrycznych Politechniki Wrocławskiej, No. 58, Studia i Materiaty, No. 25, 2005.

2. Бельй П. Н. Уравнения для проектирования встраиваемых магнитоэлектрических двигателей дискового типа // Технічна електродинаміка. 2005, № 6. С. 53-56.

3. Jacek F. Gieras. Permanent magnet motor technology / Jacek F. Gieras // Design and applications. CRC Press Taylor and Francis Group. London, New Jork, 2010.

4. Маляр В. С. Расчет магнитной иепи однофазного асинхронного двигателя с расщепленными полюсами / В. С. Маляр, Л. И. Глухивский, А. В. Маляр, Д. П. Гречин, И. Р. Гавдьо // Энергетика. Известия высших учебных заведений и энергетических обьединений СНГ. Минск. 2003, № 3. С. 17-25.

5. Maliar V. Mathematical model of permanent magnets direct current motor / V. Maliar, I. Havdo II Computational Problems of Electrical Engineering, Львiв, 2015, No. 1, Vol. 5, pp. 33-36. 


\title{
I. Р. Гавдьо
}

\section{References}

1. Dudzikowski I. Silniki komutatorowe wzbudzane magnesami trwalymi // Prace Naukowe Instytutu Maszyn, Napędów i Pomiarów Elektrycznych Politechniki Wrocławskiej, No. 58, Studia i Materiały, No. 25, 2005.

2. Belyi P. N. Uravnienia dla proektirovania vstraivaemych magnitoelektriczeskich dvigatelej diskovoho tipa// Techniczna elektrodynamika. 2005, No. 6, pp. 53-56.

3. Jacek F. Gieras. Permanent magnet motor technology / Jacek F. Gieras // Design and applications. CRC Press Taylor and Francis Group. London, New Jork, 2010.

4. Maliar V. Rasczet magnitnoj tsepi odnofaznoho asinchronnoho dvigatela s rasczeplennymi poliusami / V. Maliar, L. Hluchivskij, A. Maliar, D. Hreczyn, I. Havdo // Energetika. Izvestija vysshych uczebnych zavedenij $i$ energeticzeskich obedynenij SNH. Minsk. 2003, No. 3, pp. 17-25.

5. Maliar V. Mathematical model of permanent magnets direct current motor / V. Maliar, I. Havdo // Computational Problems of Electrical Engineering, Львiв, 2015, No. 1, Vol. 5, pp. 33-36.

I. R. Havdo

Lviv Polytechnic National University, Department of Electromechatronics and Computerized Electromechanical Systems, fireballua402@gmail.com

(C) Havdo I. R., 2019

\author{
MATHEMATICAL MODEL OF MAGNETIC STATE \\ OF PERMANENT MAGNET DIRECT CURRENT MOTOR
}

There is a tendency of replacement of small direct current motors with electromagnetic excitation on permanent magnet direct current (PMDC) motors nowadays. PMDC motors are widely used and that is why a task of creation of mathematical models of this type of motor is actual. The aim of the article is creation of mathematical model of magnetic state of PMDC motors on the basis of theory of electric and magnetic circuit. This mathematical model gives an opportunity after these values of curve of demagnetization of the magnet and instantaneous values of currents of armature to find distribution of magnetic flux (inductions) in all parts of magnetic core of motor. The mathematical model of PMDC motor is created on the basis of the ramified equivalent circuit of magnetic core with the concentrated parameters and with the high level of working out in detail of magnetic core. The magnetic core of PMDC motor is conditionally divided in to separate areas. In every area consider the magnetic field homogeneous. To the areas of magnetic core from electrical engineering steel and tooth layer of armature on a equivalent circuit is corresponded by nonlinear magnetic resistance. These resistance is set by descriptions of $\mathrm{F}[\Phi]$ as by dependences of magnetomotive forces on magnetic flux. Areas with an air gap are corresponded by permanent magnetic resistance. A permanent magnet appears the concentrated magnetomotive force that is set by description of demagnetization curve of $F_{M}\left[\Phi_{M}\right]$. The armature with an air gap divide radial planes into $s=m+n$ areas within the limits of pole pitch. From them $\boldsymbol{m}$ of even areas corresponded part of armature, that is under a magnet and $n$ of even areas - in space between magnets. The initial system of equations is written for one pole pitch after the method of contour flux that are primary unknown. The initial system of equations transforms - the magnetomotive forces on nonlinear resistance are presented by dependences on the flux of branches. Description of demagnetization of the magnet is presented equations of line that is located in the second quadrant and crosses the axis of $X$ in the point of remaining magnetic flux of $\Phi_{r}$, and axis of $Y$ in a point that corresponded complete magnetomotive force of the magnet $-F_{c}$. The nonlinear system of equations of algebra it is expedient to decide an iteration Newton method. Mathematical model of magnetic state of PMDC motors can be fixed in basis of creation of mathematical models of calculation of transients and steady state of this type of motor.

Key words: direct current motor; permanent magnet; magnetic core; equivalent circuit; system of equations; mathematical model. 